\title{
THE EFFECTIV ENESS OF SINGLE SHOT INTRAVESICAL CHEMOTHERAPY WITH MITOMYCIN-C IN PREVENTING RECURRENCE OF NON-MUSCLE INVASIVE BLADDER CANCER
}

\author{
Faiz-Ur-Rehman ${ }^{1}$, Bilal Khattak ${ }^{1}$, Irfan-UI-Islam Nasir ${ }^{1}$, Muhammad Naeem ${ }^{1}$ \\ 1. Town Teaching Hospital
}

\begin{abstract}
OBJECTIVES:

To determine the efficacy of single dose intravesi cal chemotherapy with Mitomycin-C following transurethral resection of non-muscle invasive bladder cancer

\section{METHODS:}

It was a Descriptive case series study conducted in the admitted patients of bladder cancer in the institute of kidney disease, Peshawar within one year duration. Total of 128 patients were enrolled in the study. After TURBT patient were catheterized with 22 FR 3 ways foley's catheter and urinary bladder irrigation was started with normal saline. Mitomycin $40 \mathrm{mg}$ dissolved in $20 \mathrm{ml}$ of normal saline was instilled once hematuria settles within 24 hours. All the patients were called back after 3 months for check cystoscopy and the findings were recorded so as to detect recurrence of bladder tumor
\end{abstract}

\section{RESULTS:}

In this study, 128 patients with transurethral resection of non -muscle invasive bladder cancer have been observed; male to female ratio was 5:1. The age ranges of patients were from 18 to 75 years. Average age was 51.13 years $\pm 14.33 S D$. Recurrence was found in $20(15.62 \%)$ of cases while the remaining $108(84.38 \%)$ were free of recurrence.

\section{CONCLUSION:}

Our study confirmed the effectiveness of a single shot immediate Mitomycin-C instillation in patients with nonmuscle-invasive bladder tumors.

KEY WORDS:

Mitomycin-C, transurethral resection, bladder cancer, muscle invasive, Efficacy

\section{INTRODUCTION}

Bladder cancer is one of the commonest urological cancer diagnosed world wide..$^{1}$ In the United States in 2011, there were an estimated number of new cases approximately 69,000 with

Correspondence:

Dr. Bilal Khattak

Town Teaching Hospital

Contact:0333-9254986

Email: drbilalkhattak@yahoo.com

https://doi.org/10.37762/jgmds.2-2.52 high mortality. ${ }^{2}$ Urological malignancy is common in Pakistan as well as the developed regions of the world. ${ }^{3}$ Tobacco smoking, chemicals, dye, rubber, petroleum, leather and artificial sweeteners are predisposing factors causing bladder cancer. Most common presentation of bladder cancer is painless $h$ aematuria with lower

urinary tract symptoms. Depending on the bladder muscle invasion, bladder cancer can be divided into non muscle invasive bladder cancer (stage Ta, Tis and T1) which constitutes $75 \%$ of newly diagnosed cases and muscle invasive bladder cancer (stage T24). ${ }^{1,4}$ Treatment modalities include Trans-Urethral Resection Bladder Tumor (TURBT) with intravesical chemotherapy or intravesical immunotherapy, radical cystectomy, systemic chemotherapy and radiotherapy. The treatment and management of NMIBC ultimately depends on the patient's risk of recurrence and progression. ${ }^{5}$ Following transurethral resection non-muscle invasive bladder cancer have a high rate of recurrence $(25-40 \%)$ in the first year. ${ }^{3}$ 


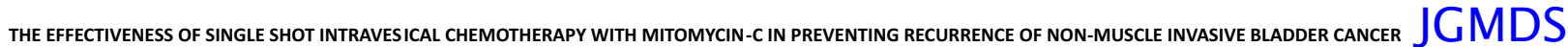

High rate of recurrence is associated with TURBT, as this is the only treatment of superficial bladder tumors (stage Ta, Tis and T1). Different chemotherapeutic agents such as mitomycin -C, thiotepa and adriamycin are available for intravesical use. Previously TURBT followed by regular check cystoscopies was routine for low grade superficial bladder cancers but now i mmediate intravescial mitomycin-C treatment is gaining popularity. ${ }^{6}$ In Jung SJ study recurrence of superficial bladder tumour after single instillation of Mitomycin-C in first year was $15 \%^{3}$ while in another study it was $11.3 \% .{ }^{7}$ Mitomycin-C is preferred for intravesical use beca use it is cheap, easily available and having least side effects. A number of studies agree with the fact that intravesical instillation of cytotoxic agents within the first 24 hours after operation reduces the risk of tumor recurrence. It is assumed that $t$ ransurethral resections of bladder tumors promote relevant intravesical tumor cell suspension that re-implants and causes cancer recurrence. ${ }^{8}$

The current study is designed to dete rmine the efficacy of mitomycin - $\mathrm{C}$ in preventing recurrence of non-muscle invasive bladder tumors in our local adult populations. Both the bladder tumors and their recurrence after TURBT is not uncommon and there is a need to identify a procedure which could at least prevent recurrence after TURBT. The idea behind doing this study developed while carefully looking at the literature in which we found most of the studies either have inadequate sample size or they have done a comparative study ${ }^{3,7}$ or even retrospective. ${ }^{7}$ So our study will be first of its kind in our local adult popula tion over adequate sample size to draw conclusive results regarding efficacy of mitomycin $-C$ in preventing recurrence of bladder tumors after TURBT and if found to be significantly high it will also be shared with other local urologists so as to recommend future guidelines for its use or further research over it.

\section{MATERIALS AND METHOD}

This study was a descriptive case series conducted at the Institute of kidney diseases, Hayatabad Medical Complex, Peshawar from $1^{\text {st }}$ January 2013 to $31^{\text {st }}$ December 2014.Sample size was 128 , using $11.3 \%{ }^{7}$ proportion of recurrence of bladder $t$ umor after TURBT with Mitomycin -C, $95 \%$ confidence interval and $5.5 \%$ margin of error under WHO sample size calculations. Sampling technique was consecutive non-probability sampling and all thepatients undergoing TURBT for the first time of either gender from $18-75$ years of age were included and exclusion criterion was all those patients who were having muscle invasive bladder tumors, patients with perforation of the bladder, gross haematuria not settling within 24 hours, incompletely resected tumor, those having recurrent bladder tumor and bladder fistula. The above mentioned conditions act as confounders and if included, introduce bias in the study results. After approval from hospital ethical committee, all patients (diagnosed as having non muscle invasive bladder tumor), who fulfill the inclusion criteria admitted in urology ward, were included in the study.

The procedure was performed under general anesthesia or spinal anesthesia dependin $g$ upon anesthetist choice. After TURBT patients were catheterized with 22 FR-Bvays foley's catheter and urinary bladder irrigation was started with normal saline. Mitomycin-C $40 \mathrm{mg}$ dissolved in 20 $\mathrm{ml}$ of normal saline was instilled once h aematuria settles within 24 hours. This solution was left in bladder for one hour with patient in supine, prone, right lateral and left lateral positions for 15 minutes each. Catheter was removed after 48 hours if $h$ aematuria is settled. All the patients were called back after 3 months for the check cystoscopy and the finding of the cystoscopy was recorded so as to detect recurrence of bladder tumor. All the above mentioned information was recorded on pre-designed Performa. Strict exclusion criteria were followed to control confounders and bias in the study results. Data was analyzed using SPSS version 16. Results were described in terms of mean and standard deviation for age. Frequency and percentages were calculated for the categorical variables like gender and age. All the results were 
shown in figures and tables. Efficacies (prevention of recurrence on check cystoscopy) were also stratified among age and gender to see the effect modifications.

\section{RESULTS}

In this study, 128 patients with transurethral resection of non -muscle invasive bladder cancer had been observed, in which $21(16.41 \%)$ were female and $107(83.59 \%)$ were male patients. Male to female ratio was 5:1.

Patients age was divided in four categories, out of which most presented in upper age i.e.41(32\%) patients were of more than 60 years and $18(14.1 \%)$ patients were in the age range of less than or equal to 30 years. Average age was 50.25 years $+15.83 S D$. (Table I)

Recurrence was found on first check cystoscopy at three months in 20(15.62\%) of cases while the remaining were free of recurrence (Figure I).

Gender wise distribution of efficacy shows that efficacy was high in male. There were 93(86.9\%) male patients showing efficacy while efficacy in female was observed in $15(71.4 \%)$ patients (Table II).

Table: 1 Age Wise Distribution Of The Patients

\begin{tabular}{|c|c|c|c|c|}
\hline \multirow{2}{*}{\multicolumn{2}{|c|}{ AGE IN YEARS }} & \multicolumn{2}{|c|}{ EFFICACY } & \multirow{3}{*}{$\begin{array}{c}\text { TOTAL } \\
18 \\
100.0 \%\end{array}$} \\
\hline & & \multirow{2}{*}{$\begin{array}{c}\text { YES } \\
17 \\
94.4 \%\end{array}$} & \multirow{2}{*}{$\begin{array}{c}\text { NO } \\
1 \\
5.6 \%\end{array}$} & \\
\hline \multirow[t]{4}{*}{ Age } & $<=30$. & & & \\
\hline & $31-45$ & $\begin{array}{c}28 \\
77.8 \%\end{array}$ & $\begin{array}{c}8 \\
22.2 \%\end{array}$ & $\begin{array}{c}36 \\
100.0 \%\end{array}$ \\
\hline & $46-60$ & $\begin{array}{c}30 \\
90.9 \%\end{array}$ & $\begin{array}{c}3 \\
9.1 \%\end{array}$ & $\begin{array}{c}33 \\
100.0 \%\end{array}$ \\
\hline & $61+$ & $\begin{array}{c}33 \\
80.5 \%\end{array}$ & $\begin{array}{c}8 \\
19.5 \%\end{array}$ & $\begin{array}{c}41 \\
100.0 \%\end{array}$ \\
\hline \multicolumn{2}{|c|}{ Tota I } & $\begin{array}{c}108 \\
84.4 \%\end{array}$ & $\begin{array}{c}20 \\
15.6 \%\end{array}$ & $\begin{array}{c}128 \\
100.0 \%\end{array}$ \\
\hline
\end{tabular}

Figure \# 1: RECURRENCE

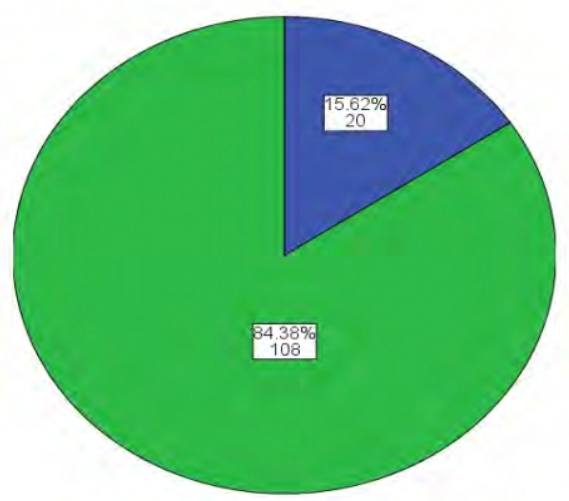


Table: 2 Gender Wise Distribution Of Efficacy

\begin{tabular}{|c|c|c|c|c|}
\hline & \multicolumn{2}{|c|}{ EFFICACY } & \multirow{2}{*}{ TOTAL } \\
\hline & & YES & NO & \\
\hline \multirow[t]{2}{*}{ Gender } & Male & $\begin{array}{c}93 \\
86.9 \%\end{array}$ & $\begin{array}{c}14 \\
13.1 \%\end{array}$ & $\begin{array}{c}107 \\
100.0 \%\end{array}$ \\
\hline & Female & $\begin{array}{c}15 \\
71.4 \%\end{array}$ & $\begin{array}{c}6 \\
28.6 \%\end{array}$ & $\begin{array}{c}21 \\
100.0 \%\end{array}$ \\
\hline Total & & $\begin{array}{c}108 \\
84.4 \%\end{array}$ & $\begin{array}{c}20 \\
15.6 \%\end{array}$ & $\begin{array}{c}128 \\
100.0 \%\end{array}$ \\
\hline
\end{tabular}

\section{DISCUSSION}

Non-muscle invasive bladder tumor accounts for about75-85 \% of bladder cases. ${ }^{9}$ The recurrence and progression rate after transurethral resection of bladder tumors (TURBT) are 50 $70 \%$ and $10-15 \%$, respectively. Risk factors for tumor recur rence and/or progression are tumor localization, tumor size, prior recurrences, presence of tumor at first follow -up cystoscopy, stage, grade and associated carcinoma in situ (CIS). ${ }^{10}$ Bladder cancer commonly affects the elderly, with the median age of 73 years at diagnosis ${ }^{11}$ which is confirmed in our study, having higher incidence $32.08 \%(41 / 128)$ in elderly. Bladder cancer incidence varies in terms of gender and ethnicity. The lifetime risk of developing bladder cancer is $3.81 \%$ for males and $1.18 \%$ for female $\mathrm{s}$, and the risk increases with advancing age. Bladder cancer is the fourth -most-common cancer in men in terms of new cases, with an incidence 4 times higher than women $(37.9$ versus 9.6 per 100,000) while in our study it came out to be 5 times higher in mal es as compare to females. In a meta-analysis of seven randomized trials, Sylvester et al. suggested that one immediate instillation of chemotherapy after TURBT decreased the percentage of patients with recurrence by $12 \%$ and the odds of recurrence by $39 \% .{ }^{12}$ Although this meta -analysis and the European Association of Urology Guidelines on Bladder Cancer recommend a single immediate postoperative installation of chemotherapy in all cases of NMIBC and adjuvant intravesical immunotherapy with BCG in patients with high risk NMIBC. ${ }^{13}$

Our study shows that the recurrence is $15.62 \%$ after single dose mitomycin $-\mathrm{C}$ installation which is comparable with a national study done by Ather $\mathrm{MH}$ and colleagues in 2007, in which recurrence was $15 \%$ after one year follo w-up with sing le dose mitomycin -C installation ${ }^{3}$, while comparing our study with international study conducted by Jung SJ and colleagues in 2011, which showed recurrence of $11.3 \%$ after single dose installation of mitomycin-C. ${ }^{7}$ Mitomycin- $C$ has a high molecular weight, resulting in a low incidence of systemic side effects with most common adverse effect being chemical cystitis reported in up to $41 \%$ of patients. The manifestations of cystitis include dysuria, frequency, urgency, supra -pubic pain, and discomfort. In addition , the incidence of decreased bladder capacity has been as high as $22 \%$ in clinical trials, with the rare need for cystectomy due to severe bladder contractures. ${ }^{14}$ Less common adverse effects include eczema like reactions ( $4 \%$ to $12 \%)$ and myelo-suppression, which is rare.

This inexpensive and safe approach spares a significant number of transurethral resections in these patients .Consequently; this approach can be considered an alternative for observation only in patients with low risk superficial bladder cancer. Our study confirmed the 


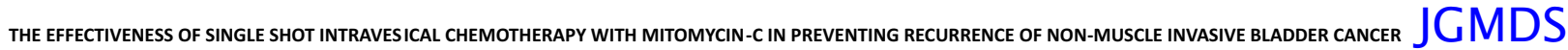

positive effect of a single mitomycin -C instillation in patients with non -muscle-invasive bladder tumors. This benefit was to control early recurrence and was not maintained with long-term followup.

\section{CONCLUSION}

In patients wi th superficial bladder cancer a single shot of mitomycin -C with in $24 \mathrm{hrs}$ of resection of tumor decreases recurrence and improves disease free interval by preventing early cell implantation. The results were more promising in male patients

\section{REFERENCES}

1. Madeb R, Golijanin D, Noyes K, Fisher S, Stephenson JJ, Long SR et al. Treatment of Non -Muscle Invading Bladder Cancer. Do physicians in the United States Practice Evidence Based Medicine? The use and economic implications of Intravesical Chemotherapy after Transurethral Resection of Bladder Tumors. Cancer. 2009;115:2660-70.

2. Siegel R, Ward E, Brawley O, Jemal A. Cancer statistics, 2011: The impact of eliminating socioeconomic and racial disparities on premature cancer deaths. CA Cancer J Clin. 2011;61:212 15.

3. Ather MH, Aziz S, SulaimanMN. Single instillation of Mitomycin C Reduces 1 st year recurrence following transurethral resection of non-muscle invasive bladder cancer. J Ayub Med Coll Abbottabad. 2007;19:18-20.

4. Dyrskjot L, Ostenfeld MS, Bramsen JB, Silahtaroglu AN, Lamy P, Ramanathan R, et al. Genomic Profiling of MicroRNAs in Bladder Cancer: miR-129 Is Associated with Poor Outcome and Promotes Cell Death In vitro. Cancer Res. 2009;69:115-24.

5. Persad R, Lammb D, Brausi M, Soloway M, Palou J, Bohle A. et al. Current Approaches to the Management of Non -Muscle Invasive Bladder Cancer: Comparison of Current Guidelines and Recommendations. european urology supplements. 2008;7:637-50.

6. Jung SJ, Chang HS, Park CH, Kim C, Kim BH. Effectiveness of an Immediate Mitomycin C Instillation in Patients with Superficial Bladder Cancer Receiving Periodic Mitomycin C Instillation. Krean J Urol. 2011;52:323-6.

7. Jung SJ, Chang HS, Park CH, Kim C II, Kim BH. Effectiveness of an Immediate Mitomycin C Instillation in Patients with Superficial Bladder Cancer Receiving Periodic Mitomycin C Instillation. Korean J Urol. 2011;52: 323-6.

8. Kaasinen E, Rintala E, Hellsrom P, Vitanen J, Juusela H, Rajala P. et al. Factors explaining recurrence in patients undergoing chemoimmunotherapy regimens for frequently recurring superficial bladder carcinoma. Eur Urol. 2007;42:167-74.

9. Babjuk M, Oosterlinck W, Sylvester R, Kaasinen E, Böhle A, Palou-Redorta J, et al. EAU guidelines on non-muscle-invasive urothelial carcinoma of the bladder. Eur Urol. 2008;54:303-14.

10. Sylvester RJ, van der Meijden AP, Oosterlinck W, Witjes JA, Bouffioux C, Denis L, et al. Pred icting recurrence and progression in individual patients with stage Ta T1 bladder cancer using EORTC risk tables: a combined analysis of 2596 patients from seven EORTC trials. Eur Urol. 2006;49:466 -5. 
11. Howlader N, Noone AM, Krapcho M. SEER Cancer Statistic Review, 1975-2008," National Cancer Institute, Bethesda, Md, USA, 2011. Available at: http://seer.cancer.gov/csr/1975 2008/.

12. Sylvester RJ, Oosterlinck W, van der Meijden AP. A single immediate posto perative instillation of chemotherapy decreases the risk of recurrence in patients with stage Ta T1 bladder cancer: a metaanalysis of published results of randomized clinical trials. J Urol. 2004;171:2186-90.

13. Babjuk M, Oosterlinck W, Sylvester R, Kaasine n E, Böhle A, Palou-Redorta J, et al. EAU guidelines on non-muscle-invasive urothelial carcinoma of the bladder. Eur Urol. 2008;54:303-14.

14. Koya MP, Simon MA, Soloway MS. Complications of intravesical therapy for urothelial cancer of the bladder. J Urol. 2006;175(6):2004-10.

\section{(c) (1)}

LICENSE: JGMDS publishes its articles under a Creative Commons Attribution Non-Commercial Share-Alike license (CC-BY-NC-SA 4.0) COPYRIGHTS: Authors retain the rights without any restrictions to freely download, print, share and disseminate the article for any lawful purpose. It includes scholarly networks such as Research Gate, Google Scholar, LinkedIn, Academia.edu, Twitter, and other academic or professional networking sites. 